\title{
Síndrome de fuga aérea torácica por enfermedad de injerto contra huésped posterior a trasplante alogénico de médula ósea
}

\section{Thoracic air leak syndrome due to graft-versus-host disease after allogeneic bone marrow transplantation}

\author{
Raúl Enrique Montero-Ureña, ${ }^{*}$ Felipe de Jesús Contreras-Rodríguez, ${ }^{\ddagger}$ Jesús Márquez-Barajas, * \\ Francisco José Anaya-Gómez,* Luis Alberto García-González,* Leonora Valdez-Rojas,* \\ Johana Jazer Garnica-Vázquez, ${ }^{*}$ Jorge Jiménez-Tornero, ${ }^{*}$ Alexandra Díaz-Alba, ${ }^{*}$ \\ Cristina Alejandra Luna-González,* Martha Georgina Álvarez-González,* \\ Yunuen García-Valadez,* Manuel Solano-Genesta*
}

\begin{abstract}
*Instituto Oncológico Nacional, Guadalajara, Jalisco, México; ”Hospital de Especialidades del Centro Médico Nacional de Occidente, Instituto Mexicano del Seguro Social, Guadalajara, Jalisco, México.
\end{abstract}

RESUMEN. Introducción: Actualmente, el trasplante de precursores hematopoyéticos es el tratamiento en neoplasias hematológicas. La enfermedad injerto contra huésped es una complicación de la introducción de dichas células. Las afecciones pulmonares son frecuentes, dentro de ellas se encuentra el síndrome de fuga aérea torácica. Caso clínico: Varón de 22 años quien padece leucemia mieloblástica aguda, postrasplante de productores alogénicos de elementos sanguíneos, que ingresó por neumotórax espontáneo recidivante. Se descartan procesos infecciosos y se toman biopsias, con reportes compatibles a enfermedad de injerto contra huésped. El tratamiento fue mediante sonda endopleural y pleurodesis bilateral, arrojando adecuada resolución del cuadro posterior a esta última. Conclusión: El síndrome de fuga aérea torácica es una complicación en el pulmón, no infecciosa, tardía y rara de la introducción de precursores hematopoyéticos, caracterizada por neumotórax espontáneo que se asocia con un mal pronóstico.

Palabras clave: Síndrome de fuga aérea torácica, enfermedad de injerto contra huésped, trasplante alogénico de médula ósea, anti-Ro52.

\section{Correspondencia:}

\section{Manuel Solano-Genesta}

Instituto Oncológico Nacional. Guadalajara, Jalisco, México.

Correo electrónico: manuelsolano@iononcologia.com.mx

Recibido: 16-XI-2020; aceptado: 07-IV-2021.

Citar como: Montero-Ureña RE, Contreras-Rodríguez FJ, Márquez-Barajas J, Anaya-Gómez FJ, García-González LA, Valdez-Rojas L, et al. Síndrome de fuga aérea torácica por enfermedad de injerto contra huésped posterior a trasplante alogénico de médula ósea. Neumol Cir Torax. 2021; 80 (2): 118-121. https:// dx.doi.org/10.35366/100993
ABSTRACT. Introduction: Currently, hematopoietic stem cell transplant (HSCT) is a treatment for hematological neoplasms. Graft-versus-host disease (GVHD) is a complication of HSCT, pulmonary involvements are frequent, among them is thoracic air leak syndrome (SFAT). Clinical case: 22-year-old male with acute myeloblastic leukemia (AML), post allogeneic HSCT (HPT). In those who are admitted for recurrent spontaneous pneumothorax, infectious processes are ruled out and biopsies are taken with reports compatible with GVHD. Treatment was by endopleural catheter and bilateral pleurodesis, with adequate resolution of the condition after the latter. Conclusion: SFAT is a rare and late non-infectious lung complication of HPT, characterized by spontaneous pneumothorax. Which is associated with a poor forecast.

Keywords: Thoracic air leak syndrome, graft versus host disease, allogeneic bone marrow transplantation, anti-Ro52.

\section{INTRODUCCIÓN}

Actualmente, el trasplante de precursores hematopoyéticos (TPH) es el tratamiento de elección para muchos trastornos graves, congénitos o adquiridos, del sistema hematopoyético. ${ }^{1}$ Las complicaciones pulmonares tienen alta morbimortalidad en pacientes pos-TPH alogénico, pues suelen presentarse en un $30-60 \%{ }^{2,3}$ Dentro de las complicaciones en los pulmones, el neumotórax es una presentación rara y la mayoría de los enfermos tienen antecedente de enfermedad crónica de injerto contra huésped (EICH).4,5 El síndrome de fuga aérea (SFAT) es una de las patologías asociadas a EICH, comúnmente causado por alguna ruptura 
alveolar, la cual conduce a enfisema intersticial de esos pulmones, que se desplaza hacia el centro a lo largo de las vainas broncovasculares en dirección al hilio pulmonar, el mediastino o la cavidad pleural.

\section{PRESENTACIÓN DEL CASO}

Paciente masculino de 22 años con diagnóstico de leucemia mieloblástica aguda (LMA), tratamiento vía quimioterapia esquema $7+3$ y consolidaciones con dosis altas Ara-C (HDAC). Recaída en un año con reinducción esquema GEMIA (mitoxantrona, Ara C y etopósido), se realiza TPH alogénico de donador relacionado con un mismatch. Profilaxis para $\mathrm{EICH}$ utilizando metrotexato y tacrolimus. $\mathrm{EICH}$ crónica en piel, hígado, mucosas y bronquiolitis obliterante neumonía organizada (BONO) manejada usando esteroides inhalados por neumología.

Cuatro años posterior a TPH alogénico, acude por dolor súbito en hemitórax izquierdo y disnea. A la exploración física del tórax simétrico, evidencia disminución a la amplexión y amplexación en hemitórax a la izquierda, ausencia de ruidos respiratorios en zona apical ipsilateral; radiogra- fía de tórax revelando colapso pulmonar izquierdo 30\% aproximadamente (Figura 1A). Por su izquierda se coloca catéter de pequeño calibre al interior de la pleura y oxígeno suplementario. Los estudios de laboratorio arrojaron biometría hemática normal, transaminasas elevadas por antecedente de $\mathrm{EICH}$ hepático y reactantes de fase aguda negativos. Tomografía simple de tórax con patrón en vidrio despulido y neumotórax izquierdo (Figura 1B).

Una semana más tarde, se realizó broncoscopia con fines de análisis de líquido bronquial y tejido pulmonar, el cual reportó tinción de bacilos ácido-alcohol resistentes (BAAR), Gram, hidróxido de potasio $(\mathrm{KOH})$, reacción en cadena de la polimerasa (PCR) por virus respiratorios y micobacterias tuberculosis, negativos en líquido bronquioloalveolar; además, anticuerpos antinucleares (ANA) HEp-2 por inmunoespecificidad positivos para anti-Ro52 con $184(+++)$. El estudio histopatológico reportó datos compatibles con proceso neumónico agudo de organización, asociado a cambios reactivos epiteliales de tipo inflamatorio; lavado bronquioloalveolar conformado por fondo proteináceo amorfo acompañado de escasas células epiteliales, las cuales presentaban cambios reactivos
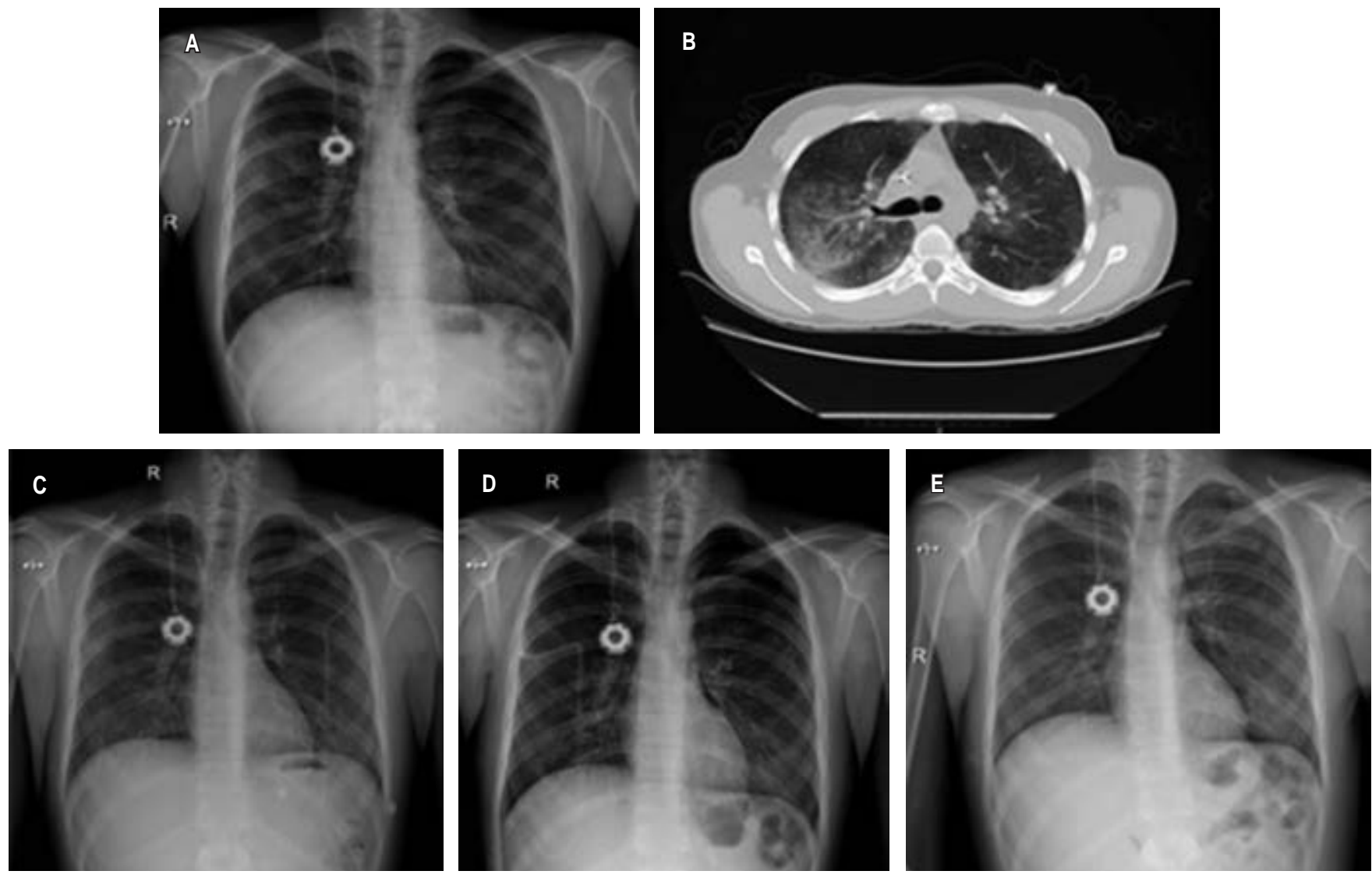

Figura 1: A) Neumotórax izquierdo. B) Tomografía con patrón en vidrio despulido. C) Reexpansión completa de pulmón izquierdo. D) Neumotórax apical izquierdo recidivante. E) Resolución de neumotórax. 

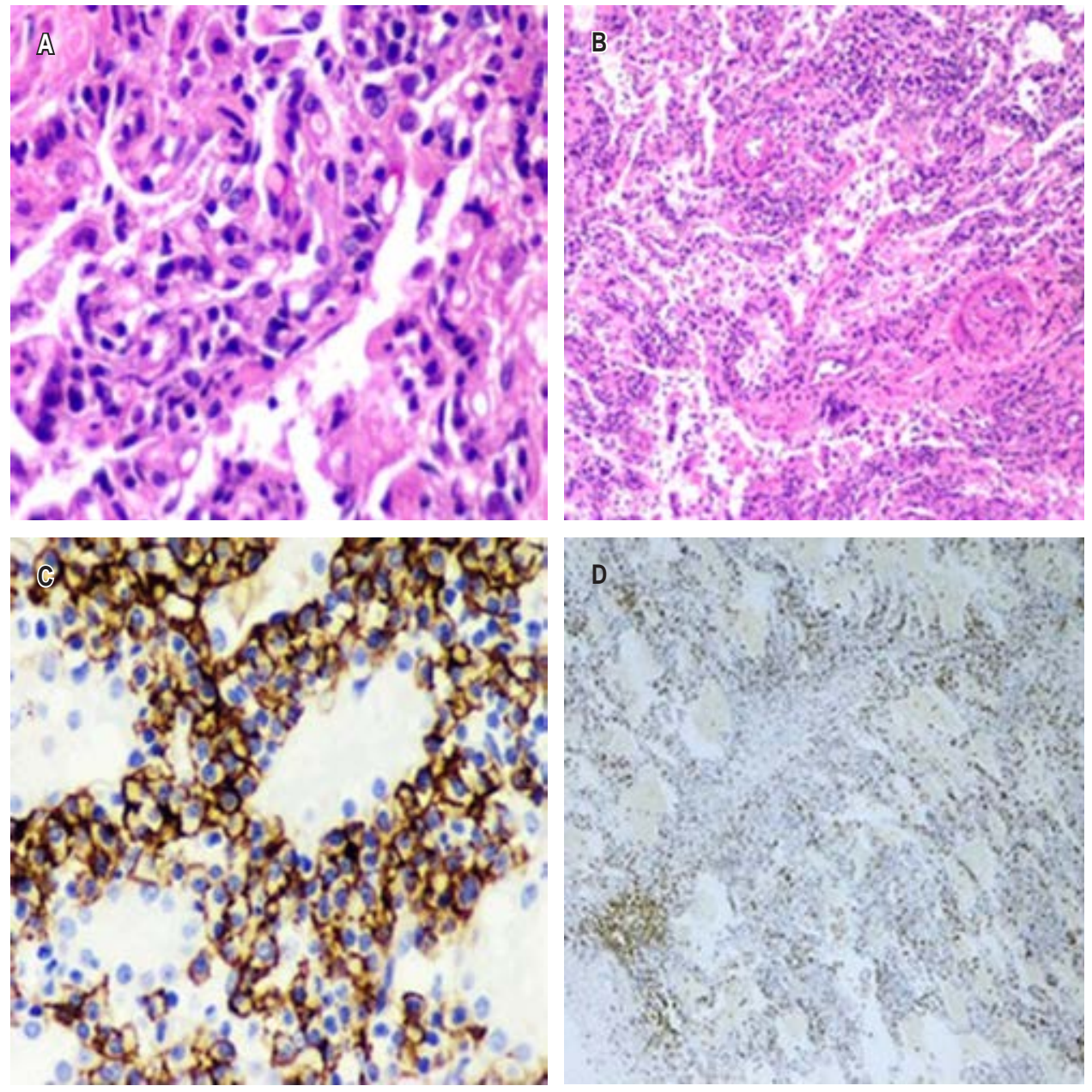

Figura 2:

Estudio histopatológico e inmunohistoquímico teñidos con hematoxilina-eosina. Producto de cuña de lóbulo inferior izquierdo con datos histopatológicos compatibles con proliferación de linfocitos pre-B, $B$ maduros y células $T$, asociadas a cambios reactivos de tipo regenerativo a nivel de parénquima pulmonar. de tipo reparativo y aisladas células inflamatorias mixtas (Figura 2). Cinco días después, se tomó radiografía con reexpansión completa de pulmón izquierdo, por lo que se retiró sonda endopleural (Figura 1C).

Un mes más adelante, reingresó por presentar de manera súbita dolor torácico derecho. A la exploración física, hemitórax derecho sin presencia de murmullo vesicular, hemitórax izquierdo con murmullo vesicular disminuido, se coloca catéter endopleural derecho de calibre reducido. Biometría hemática normal, reactantes de fase aguda negativos. Ocho días posterior al ingreso, radiografía de tórax con reexpansión pulmonar derecha; sin embargo, a la izquierda es visible pequeño neumotórax apical recidivante (Figura 1D), toracoscopia izquierda con bulectomía de lóbulo superior, biopsia de lóbulo inferior y pleurodesis química con talco. Reporte de histopatología: hallazgos histopatológicos son morfológicamente compatibles con proceso inflamatorio crónico del pulmón; por lo cual la afección de ese pulmón en un contexto de $\mathrm{EICH}$ no puede ser descartada, además, se realiza inmunohistoquímica (Figura 2); líquido pleural conformado por fondo proteináceo amorfo y eritrocitos con autólisis. Luego de quince días de su ingreso, se obtiene radiografía de tórax mostrando neumotórax apical recidivante derecho, se aplica pleurodesis química derecha a través de sonda endopleural. La siguiente semana se retiran ambas sondas pleurales y se toma control radiográfico sin recidiva de dicho colapso pulmonar (Figura 1E).

\section{DISCUSIÓN}

El presente reporte muestra la presencia de SFAT en paciente pos-TPH en forma bilateral con manifestación espontánea de neumotórax. El SFAT pos-TPH tiene reportada en la literatura una incidencia acumulada global de $3.1 \% .{ }^{6}$ Comúnmente, se presenta en un rango de tiempo entre 202-507 días pos-TPH; ${ }^{2,7}$ en este caso, se presentó el primer evento a los 1,458 días postrasplante. El factor de riesgo más común asociado es $\mathrm{EICH}$, se han descrito otros, a saber: género masculino, edad, Pneumocystis jirovecii, bacterias con cápsula, hongos, virus de la varicela zóster (VZV), citomegalovirus (CMV) y otros virus respiratorios; ${ }^{8}$ 
por este motivo se realizaron PCR buscando virus respiratorios, cultivos utilizando $\mathrm{KOH}, \mathrm{BAAR}$ y Gram de líquido bronquioloalveolar, donde se reportaron negativos. Se tomó panel inmunológico de anticuerpos antinucleares (ANA), cuyos resultados se reportaron positivos para antiRo52, mismos que se asocian a enfermedades del tejido conectivo (ETC). En ocasiones, la EICH tiene características que asemejan trastornos autoinmunitarios como esclerodermia, síndrome de Sjögren, entre otros. Se ha descrito un espectro de manifestaciones pulmonares que ocurren en enfermos quienes padecen ETC bien definida después de TPH alogénico similar a ETC idiopática, se desconoce su incidencia y por lo regular suele pasarse por alto. Se han propuesto mecanismos fisiopatológicos por los cuales se desencadenan estas manifestaciones autoinmunes, por ejemplo predisposición genética, deficiencia tímica, expresión de reconstitución anormal de células B/T o la transferencia de clones patógenos relacionados con el donante. ${ }^{9}$ Para aquellos quienes han padecido SFAT, el pronóstico suele ser pobre, con supervivencia de uno a tres años: de $45 \%$ y $15 \%$, respectivamente. ${ }^{2}$ Durante su estancia hospitalaria, el paciente resolvió su padecimiento mediante colocación de catéter pleural de pequeño calibre y pleurodesis química bilateral.

\section{CONCLUSIONES}

El SFAT es una complicación pulmonar no infecciosa, tardía y rara del TPH, el cual se caracteriza principalmente por neumotórax espontaneo en algunos casos recidivante; se deben de excluir otros procesos principalmente infecciosos, al igual que otras complicaciones más comunes de los pulmones, relacionadas con $\mathrm{EICH}$, como la BO. Suele asociarse a un mal pronóstico.

\section{REFERENCIAS}

1. Moon MH, Sa YJ, Cho KD, Jo KH, Lee SH, Sim SB. Thoracic air-leak syndromes in hematopoietic stem cell transplant recipients with graft- versus-host disease: a possible sign for poor response to treatment and poor prognosis. J Korean Med Sci. 2010;25(5):658-662. Available in: https://doi.org/10.3346/jkms.2010.25.5.658

2. Dsouza K, Pywell C, Thannickal VJ. Late noninfectious pulmonary complications in hematopoietic stem cell transplantation. In: Nates J, Price K, editors. Oncologic critical care. Cham: Springer; 2020. Available in: https://doi.org/10.1007/978-3-319-74588-6_51

3. Kapadia M, Shapiro TW. Pulmonary complications associated with HSCT. In: Brown V, editor. Hematopoietic stem cell transplantation for the pediatric hematologist/oncologist. Cham: Springer; 2018: 301-325. Available in: https://doi.org/10.1007/978-3-319-63146-2_21

4. Batllés PC, Polo JC, Caballer JS, Lletí MS, Torrero LC. Neoplasias hematológicas: interpretación de los hallazgos pulmonares en la tomografía computarizada torácica. Radiología [Internet]. 2015;57(6):455-470. Disponible en: http://dx.doi.org/10.1016/j. rX.2015.07.003

5. Ebihara Y, Yamamoto S, Mochizuki S, Tsukada M, Taya Y, Kawakita T, et al. Pneumothorax in an early phase after allogeneic hematopoietic stem cell transplantation. Hematol Rep. 2013;5(2):34-35. Available in: https://doi.org/10.4081/hr.2013.e10

6. Liu YC, Chou YH, Ko PS, Wang HY, Fan NW, Liu CJ, et al. Risk factors and clinical features for post-transplant thoracic air-leak syndrome in adult patients receiving allogeneic haematopoietic stem cell transplantation. Sci Rep. 2019;9(1):11795. Available in: https://doi. org/10.1038/s41598-019-48308-9

7. Namkoong H, Ishii M, Mori T, Sugiura H, Tasaka S, Sakurai M, et al. Clinical and radiological characteristics of patients with lateonset severe restrictive lung defect after hematopoietic stem cell transplantation. BMC Pulm Med. 2017;17(1):123. Available in: https:// doi.org/10.1186/s12890-017-0466-7

8. Inamoto Y, Lee SJ. Late effects of blood and marrow transplantation. Haematologica. 2017;102(4):614-625. Available in: https://doi. org/10.3324/haematol.2016.150250

9. Chagnon K, Schlemmer F, Meignin V, Bergeron A. Pulmonary manifestations of hematological malignancies: focus on pulmonary chronic graft-versus host disease. In: Cottin V, Cordier JF, Richeldi L, editors. Orphan lung diseases. London: Springer; 2015: 517-527. Available in: https://doi.org/10.1007/978-1-4471-2401-6_32

Conflicto de intereses: Los autores declaran no tener conflicto de intereses. 